\title{
Has the Economic Structure Optimization in China's Supply-Side Structural Reform Improved the Inclusive Green Total Factor Productivity?
}

\author{
Feng Wang, Jianxiong Wu, Min Wu*(D), Wen Zheng and Danwen Huang \\ School of Economics and Finance, Xi' an Jiaotong University, Shaanxi Province, Xi'an 710061, China; \\ wangfeng123@xjtu.edu.cn (F.W.); wujianxiong511@stu.xjtu.edu.cn (J.W.); 18252007501@163.com (W.Z.); \\ huangdanwen0413@163.com (D.H.) \\ * Correspondence: wumin2019@stu.xjtu.edu.cn
}

Citation: Wang, F.; Wu, J.; Wu, M.; Zheng, W.; Huang, D. Has the

Economic Structure Optimization in China's Supply-Side Structural Reform Improved the Inclusive Green Total Factor Productivity? Sustainability 2021, 13, 12911. https:// doi.org/10.3390/su132212911

Academic Editor: Ermanno C. Tortia

Received: 30 October 2021

Accepted: 19 November 2021

Published: 22 November 2021

Publisher's Note: MDPI stays neutral with regard to jurisdictional claims in published maps and institutional affiliations.

Copyright: (C) 2021 by the authors. Licensee MDPI, Basel, Switzerland. This article is an open access article distributed under the terms and conditions of the Creative Commons Attribution (CC BY) license (https:/ / creativecommons.org/licenses/by/ $4.0 /)$.
Abstract: One of the goals of China's supply-side structural reform is to improve total factor productivity (TFP). Considering the problems of environmental deterioration and income disparity faced by China, this paper first incorporates environmental pollution and income disparity as undesirable outputs into the TFP analysis framework, and extends the concept of inclusive green TFP (henceforth IGTFP).We measure and analyze the IGTFP in China's provinces from 1995 to 2017 using the Malmquist-Luenberger index, and then examine, for the first time, the impacts of economic structural optimization in the supply-side structural reform on the IGTFP. The results are shown as follows. First, China's national IGTFP index is significantly smaller than the traditional TFP index. That is, the traditional TFP without the constraints of environmental pollution and income disparity overestimates China's real TFP. Second, there are significant regional differences in China's IGTFP, the average annual growth rate of IGTFP shows a gradual downward trend from east to west. This would further exacerbate the regional imbalance in China's economic development. Third, among the structural factors in economic structure optimization, industrial structure and energy structure are negatively correlated with the IGTFP, while factor structure, labor structure and urban-rural structure are all positively correlated with the IGTFP. These results imply that the economic structure optimization driven by supply-side structural reform will improve China's IGTFP.

Keywords: supply-side structural reform; inclusive green growth; inclusive green TFP; structural optimization; Malmquist-Luenberger index

\section{Introduction}

Since the reform and opening- up, China's economic development has made worldrenowned achievements and achieved unprecedented historical changes. However, with the rapid economic growth, China's economic and social development is facing new problems and challenges. On the one hand, the extensive economic growth model driven by investment and factors in the long- run, has gradually led to the severe resource and environmental problems, and energy consumption and pollutant emissions have approached the environmental carrying limit. Therefore, this economic development model with high pollution, high energy consumption and high emissions is unsustainable [1] On the other hand, with the rapid growth of the economy, the income gap between Chinese residents has widened, and the polarization of wealth has become increasingly serious [2]. According to the data released by the National Bureau of Statistics, China's Gini coefficient rose from about 0.3 in 1980 to 0.484 in 2007 and has remained above the international warning line of 0.4 since then, reaching 0.474 in 2018 [3]. Facing the growing problems of environmental pollution and wealth polarization, China must transform its economic development model, ensure the quality of economic development while pursuing high growth, and achieve green and inclusive growth. The concept of inclusive green 
development was first proposed at the Rio+20 Summit in 2012, aiming to address the problems of social inequality and environmental pollution. It is an important way to promote the coordinated development of society, environment and economy [4]. Inclusive green total factor productivity is derived from the concept of inclusive green development, which is the total factor productivity (TFP) that includes the inclusiveness and greening of the economy. Therefore, enhancing inclusive green TFP (simply IGTFP hereafter) is the key for transition to an economy with low pollution and inclusive growth, and the fundamental path to achieve high-quality economic development.

In this context, to solve these problems in the process of economic development, China started to implement supply-side structural reform [5]. In November 2015, China first introduced the concept of "supply-side structural reform", and further clarified it in December, emphasizing that the focus of supply-side structural reform was to liberate and develop social productive forces, promote structural adjustment utilizing reform, reduce ineffective and low-end supply, expand effective and middle- and high-end supply, enhance the adaptability and flexibility of the supply structure to changes in demand and improve the TFP. In 2017, the 19th National Congress report pointed out that it was necessary to take the supply-side structural reform as the mainline to promote quality change, efficiency change and power change in economic development and to improve the TFP. These show that optimizing economic structure in supply-side structural reform is an important way to enhance the IGTFP.

Therefore, how does China's IGTFP differ from traditional TFP? What are the characteristics of the IGTFP in terms of growth trend and regional distribution? What are the impacts of economic structure optimization in supply-side structural reform on the IGTFP? In order to answer these questions, this paper constructs a model to measure the IGTFP by introducing environmental pollution and income disparity into the TFP research framework, and measures and analyzes the IGTFP in China's provinces from 1995 to 2017; on this basis, this paper takes into account the policy context of supply-side structural reform, scientifically and systematically selects structural optimization indicators, and examines, for the first time, the contribution of structural optimization in supply-side structural reform to enhancement of the IGTFP. This study not only makes a marginal contribution to the research in this field but also has an important reference value for the practical activities of realizing green and inclusive economic growth in China.

This paper makes three contributions to the literature. First, for a long time, the literature related to TFP has mostly focused on measuring traditional TFP or green TFP including environmental factors and rarely regarded the issue of income disparity. This may lead to a biased evaluation of economic efficiency and, thus, misleading recommendations [6]. In this paper, we introduce environmental pollution and income disparity as undesirable outputs into the TFP research framework and construct an IGTFP measurement model to improve the accuracy and reliability of measuring China's TFP. Second, the key to studying TFP lies in the accurate measurement of TFP. Most of the existing literature uses stochastic frontier analysis to measure TFP. However, the method must explicitly set the specific distribution of the production function, which has strong theoretical limitations and does not fit the complex socio-economic pattern in China. Based on the directional distance function model, this paper uses Data Envelopment Analysis (DEA), the Malmquist index and Malmquist-Luenberger index to measure Chinese traditional TFP and IGTFP. Third, the ultimate purpose of analyzing TFP is to find the key factors influencing economic growth. Economic development is closely related to national policies, only, when considering the current national policies, it is more realistic to analyze the influencing factors of TFP. However, the existing literature hardly considers the policy context when selecting the factors affecting TFP and fails to fully reveal the effects of supply-side structural reform on TFP. Therefore, this paper examines, for the first time, the impacts of structural optimization in supply-side structural reforms on China's IGTFP in the context of current policies.

The rest of this paper is organized as follows. Section 2 reviews the relevant literature. Section 3 constructs the IGTFP measurement model. Section 4 analyzes the characteristics 
of the IGTFP in China's provinces. Section 5 establishes a panel data model of the impact of supply-side structural reform on the IGTFP, and then analyzes and discusses the estimation results. Section 6 presents the conclusions and policy implications.

\section{Literature Review}

Since Solow proposed the analytical framework of TFP, TFP has been widely introduced into neoclassical growth accounting as an important engine driving economic growth beyond traditional input factors [7]. In the past four decades, China's economic development has made world-renowned achievements and been called the "growth miracle". At present, a large number of studies on China's TFP have focused on measuring TFP and investigating its influencing factors.

The early studies on China's TFP only took labor and capital as input factors and GDP as desirable output, and the analytical framework was not yet complete. Later, as the negative impact of environmental issues on China's sustainable development became increasingly prominent, some scholars began to incorporate environmental pollution into the TFP model, and proposed the concept of green TFP [8-16]. Chen and Golley suggested that the green TFP estimated by treating environmental pollution as an undesired output was significantly lower than the traditional TFP, that is, the traditional TFP in China was greatly overestimated for a long time [9]. The development of the concept of green TFP has enriched the theoretical foundation of TFP and improved its analytical framework. Currently, China's economic development has entered a new normal. With the continuous expansion of the total economic output, wealth polarization has become more and more obvious. This unequal growth with a widening gap between the rich and the poor has seriously deviated from the inclusive development direction, posing serious challenges to the sustainable development of the economy and society [17]. Therefore, Chen and Qin introduced income disparity as an undesired output into the TFP model and proposed the concept of inclusive TFP [18]. They estimated inclusive TFP in China's provinces from 1980 to 2011 and found that the inclusive TFP was significantly smaller than the traditional TFP, which shows that China's TFP would be greatly overestimated without considering the income gap. Afterward, Ge et al. [16] measured inclusive TFP in China's 281 cities from 2004 to 2016 referring to the study of Chen and Qin [18]. It can be found that the existing literature studying green TFP hardly considers the possible negative impact of the wealth gap on TFP growth, and the literature related to inclusive TFP ignores the environmental pollution issue. Therefore, the impacts of environmental pollution and the income gap should be considered when measuring China's TFP so as to measure China's real TFP more accurately.

In terms of the estimation methods of TFP, the accuracy of estimation has been improving from the initial algebraic index method and Solow's residual method to the stochastic frontier approach (SFA) and DEA. Although the algebraic index method can reflect the meaning of TFP, it assumes that labor and capital can be fully substituted, which is seriously inconsistent with the reality; although the Solow residual method is an improvement compared to the algebraic index method, it attributes the growth of TFP exclusively to technological progress and does not consider the gap between the technological frontier and the production units. To overcome the shortcomings of the first two methods, Aigner et al. considered the effect of relative technical efficiency on TFP and proposed the stochastic frontier analysis in 1977 [19]. Thereafter, a large number of scholars have started to use this method to study the growth of TFP [20-22]. The SFA takes the influence of relative technical efficiency on TFP into account, which can avoid the interference of random disturbance terms to a certain extent. However, using the SFA has to presuppose the specific distribution of the production function, which makes the method highly theoretically constrained and does not fit the current situation of China's complex economic development. In order to overcome the theoretical shortcomings of the SFA and avoid the bias of setting a parameterized model, some studies measured the traditional TFP or green TFP by combining DEA with the Malmquist index or Malmquist-Luenberger index [23-29]. As a nonparametric model, DEA does not need to set a specific functional form. It can 
not only overcome the shortcomings of the SFA model set which is prone to bias, but also can analyze multiple inputs and multiple outputs, making the measurement results more scientific and objective.

In addition to studies on the TFP measurement and characteristics' analysis, much of the literature has also investigated the influencing factors of TFP, green TFP and inclusive TFP. In their study exploring the influencing factors of traditional TFP, Li et al. examined the impact of higher education on China's TFP and found that this impact had a significant U-shaped characteristic, higher education development would have a positive impact on TFP when the ratio of college graduates to population exceeded 32.3\% [30]. Sun et al. studied the influencing factors of tourism TFP in China and showed that the levels of economic development and service industry development had a significant impact on tourism TFP, while the effects of transportation accessibility and tourism human capital were not significant [31]. Li et al. examined the impact of internet development on green TFP in China using a threshold regression model and a fixed effects model, and their findings indicated that internet development, human capital, urbanization, energy efficiency, and external dependence all positively influenced green TFP [32]. Liu and Xin evaluated the impact of China's Belt and Road Initiative on green TFP, and found that the marketization of land transfer and the rationalization of industrial structure significantly contributed to the improvement of green TFP, and this contribution remained significant at the regional level [33]. Tao et al. found that capital-labor ratio, environmental regulations and energy consumption structure, measured by the share of electricity consumption, all had significant positive effects on China's green TFP, while the share of foreign direct investment had a significant negative effect [34]. Zhang and Tan conducted an empirical analysis using data from 285 prefecture-level cities in China from 2005 to 2012 [35]. The results showed that per capita urban road area, number of internet users, fiscal expenditure ratio, level of environmental regulation and technology input were positively related to green TFP, while the share of value added in secondary industry and foreign direct investment were negatively related to green TFP. Liu et al. analyzed the influencing factors of green TFP in China's agriculture [25]. They found that agricultural factor endowments and regional characteristics would influence agricultural green TFP and there were regional differences in the degree of influence. In addition, some scholars have also examined the influencing factors of inclusive TFP. Ge et al. conducted an empirical study based on Chinese municipal data from 2004 to 2016 and found that the loss of environmental regulation efficiency inhibited inclusive TFP growth [3].

Although no studies analyzing the impact of the supply-side structural reform on China's IGTFP have been found in the searchable literature, some scholars have examined the effects of supply-side structural reform on green development or inclusive development. In terms of the reform's impact on green development, $\mathrm{Xu}$ and Zhuang analyzed the driving effect of supply-side reform on China's industrial green development based on the dynamic panel system GMM estimation method [36]. They found that the supply of green factors such as population quality, clean energy, green technology, green industry and environmental regulation had promoted the green development of China's industry, while green capital had a " $U$ " shaped relationship with industrial green development. Wang et al. examined the impact of supply-side factors on the industrial green development of Beijing, Tianjin and Hebei in China [37]. Their results showed that R\&D investment and corporate profitability had a facilitating effect on industrial green development, while government regulation had an inhibiting effect on industrial green development. For the impact of supply-side structural reform on inclusive development, Song et al. explored the relationship between supply-side structural reform and inclusive growth in China's agriculture [38]. The results suggested that agricultural supply-side structural reform was conducive to inclusive growth. Zhang and Zheng examined the income distribution effect of China's industrial structure adjustment based on the fixed effect model, and found that in the process of supply-side structural reform, industrial transformation and upgrading in Zhejiang could effectively narrow the urban-rural income gap [39]. 
The above literature review reveals the following three points. First, the existing literature on TFP mainly focuses on the green TFP and rarely involves discussions on the wealth gap. No studies have been found in the searchable literature that consider both environmental pollution constraints and income disparity constraints in measuring TFP. Second, the existing literature has also examined the influencing factors of TFP. However, on the one hand, these studies have mainly investigated the influencing factors of traditional TFP or green TFP; on the other hand, from the perspective of supply-side structural reform, these studies have only examined the influence of some structural optimization indicators on TFP, but failed to reveal the effects of structural optimization on TFP comprehensively and systematically. Third, some literature also evaluated the impact of supply-side structural reform on green development or inclusive development, but failed to focus on its impact on inclusive green development. Therefore, this paper takes IGTFP including environmental factors and income disparity as a measure of high-quality economic development, analyzes in depth the growth trend and regional characteristics of China's IGTFP, and further employs a panel data model to examine, for the first time, the contribution of structural optimization in supply-side structural reform to enhancement of the IGTFP.

\section{Methodology and Data of Measuring IGTFP}

\subsection{Methodology}

In this paper, we measure the IGTFP of China's provinces by the Malmquist-Luenberger index based on the directional distance function.

\subsubsection{Directional Distance Function}

Following the idea of Färe et al. [40], we treat each province in China as a production decision unit (DMU) and define each province's input factors in production as $x \in R_{+}{ }^{N}$, desired outputs as $y \in R_{+}{ }^{M}$ and undesirable outputs as $b \in R_{+}{ }^{I} . N, M$, and $I$ denotes $N$ inputs, $M$ desired outputs and $I$ undesirable outputs, respectively. Since this paper aims to measure the IGTFP, we introduce three input factors (capital, labor and energy) in the production function, treat real GDP as the desired output and consider pollutant emissions and income gap as the undesirable outputs. Although the income gap is generated in the income distribution, the differences in the industries, occupations and jobs in which residents are engaged in economic production activities, or even different labor in the same job, are the real causes of the income gap. Therefore, the income gap is essentially the result of production. In this sense, we can incorporate the income gap as an undesired output in the production function.

Assume that $P(x)$ is the set of production possibilities, $P(x)=\{(y, b): x$ can produce $(y, b)\}$, and $P(x)$ satisfies the properties of convexity, zero binding, free disposability of desired outputs and weak disposability of joint outputs. $P(x)$ gives the possible frontier of outputs after considering undesirable factors and is the basis for measuring the IGTFP.

According to Chung et al. [41], to calculate the IGTFP including environmental factors and income disparity factors, a directional distance function could be introduced on the basis of the production possibility set $P(x)$.

$$
\vec{D}_{0}(x, y, b ; g)=\sup \{\beta:(y, b)+\beta g \in p(x)\}
$$

where $g=\left(g_{y}, g_{-b}\right)$ is the direction vector, $g \in R^{M} \times R^{I}$. This vector is used to constrain the direction and magnitude of changes in desired and undesired outputs. $B$ denotes the maximum multiple of the output vector $(y, b)$ that can be expanded along the direction vector $g$ for a given amount of input $x . \beta=0$ indicates that the production decision unit is most efficient on the frontier production plane. 
The solution of the directional distance function can be obtained by the following DEA model:

$$
\begin{aligned}
& \vec{D}_{0}^{t}\left(x^{t}, y^{t}, b^{t} ; y^{t},-b^{t}\right)=\max \beta \\
& \text { s.t. } \\
& \left\{\begin{array}{l}
\sum_{k=1}^{K} z_{k}^{t} y_{k m}^{t} \geq(1+\beta) y_{k m^{\prime}}^{t}, m=1,2, \cdots M ; \\
\sum_{k=1}^{K} z_{k}^{t} b_{k i}^{t}=(1-\beta) b_{k i}^{t}, i=1,2, \cdots I ; \\
\sum_{k=1}^{K} z_{k}^{t} x_{k n}^{t} \leq x_{k n}^{t}, n=1,2, \cdots N ; \\
z_{k}^{t} \geq 0 ; k=1,2, \cdots K
\end{array}\right.
\end{aligned}
$$

where $x, y$ and $b$ denote input factors, desired outputs and undesirable outputs, respectively; $k$ refers to the $K$ production decision units; $N, M$ and $I$ represent the types of input factors, desired outputs and undesirable outputs, respectively; $\beta$ denotes the value of the directional distance function that maximizes desired output $y$ and minimizes undesirable outputs $b$ in period $t ; z$ is the weight and the share of the output value of each production decision unit in GDP is used as the weight in this paper.

The first and third constraints in the linear programming model shown in Equation (2) impose strong disposability of the desired output and input factors, respectively. The desired output is assumed to be arbitrarily disposable, while the undesirable output is assumed to be constant. These two constraints combined with the second constraint reflect the joint weak disposability of desired and undesirable outputs. That is, when undesirable output decreases, desired output also has to decrease at the same time, reflecting the cost of lowering undesirable outputs. Finally, the non-negativity constraint on the intensity variable $\mathrm{z}$ indicates that the model is allowed to exhibit constant returns to scale.

\subsubsection{Malmquist-Luenberger Index}

The Malmquist index (M-index) was originally proposed by Malmquist in 1953. In 1994, Färe and Grosskopf combined the theory with DEA to make the M-index widely available for measuring traditional TFP [42]. However, the traditional measurement model of TFP contains only input factors and desired outputs. To measure TFP including undesirable outputs, Chung et al. applied the directional distance function to calculate TFP [41]. They generalized the Luenberger profit function based on the M-index, constructed an evaluation framework of productivity based on the directional distance function, and proposed the Malmquist-Luenberger index (ML-index). The ML-index can be used to measure the IGTFP including undesirable outputs such as pollutant emissions and income disparity

$$
M L_{t}^{t+1}=\left[\frac{1+\vec{D}_{0}^{t}\left(x^{t}, y^{t}, b^{t} ; y^{t},-b^{t}\right)}{1+\vec{D}_{0}^{t}\left(x^{t+1}, y^{t+1}, b^{t+1} ; y^{t+1},-b^{t+1}\right)} \times \frac{1+\vec{D}_{0}^{t+1}\left(x^{t}, y^{t}, b^{t} ; y^{t},-b^{t}\right)}{1+\vec{D}_{0}^{t+1}\left(x^{t+1}, y^{t+1}, b^{t+1} ; y^{t+1},-b^{t+1}\right)}\right]^{1 / 2}
$$

where $\vec{D}_{0}^{t}\left(x^{t}, y^{t}, b^{t} ; y^{t},-b^{t}\right)$ and $\vec{D}_{0}^{t+1}\left(x^{t+1}, y^{t+1}, b^{t+1} ; y^{t+1},-b^{t+1}\right)$ denote the distance functions in periods $t$ and $t+1$, respectively; $\vec{D}_{0}^{t}\left(x^{t+1}, y^{t+1}, b^{t+1} ; y^{t+1},-b^{t+1}\right)$ and $\vec{D}_{0}^{t+1}\left(x^{t}, y^{t}, b^{t} ; y^{t},-b^{t}\right)$ refer to the hybrid distance functions under the technical conditions in the $t$-period and the $t+1$-period, respectively. The ML-index represents the change in TFP from period $t$ to period $t+1$. ML-index greater than 1 indicates productivity growth and that less than 1 indicates productivity decline.

To further investigate technological progress and efficiency improvement, the ML-index can be decomposed into the product of the index of efficiency change (ML-EFFECT) and the index of technological progress (ML-TECH). 


$$
\begin{gathered}
M L-\operatorname{EFFECT} T_{t}^{t+1}=\frac{1+\vec{D}_{0}^{t}\left(x^{t}, y^{t}, b^{t} ; y^{t},-b^{t}\right)}{1+\vec{D}_{0}^{t+1}\left(x^{t+1}, y^{t+1}, b^{t+1} ; y^{t+1},-b^{t+1}\right)} \\
M L-T E C H_{t}^{t+1}=\left[\frac{1+\vec{D}_{0}^{t+1}\left(x^{t}, y^{t}, b^{t}, y^{t},-b^{t}\right)}{1+\vec{D}_{0}^{t}\left(x^{t}, y^{t}, b^{t} ; y^{t},-b^{t}\right)} \times \frac{1+\vec{D}_{0}^{t+1}\left(x^{t+1}, y^{t+1}, b^{t+1} ; y^{t+1},-b^{t+1}\right)}{1+\vec{D}_{0}^{t}\left(x^{t+1}, y^{t+1}, b^{t+1} ; y^{t+1},-b^{t+1}\right)}\right]^{1 / 2}
\end{gathered}
$$

where the ML-EFFECT index indicates the change in the distance between the real output of the production decision unit and the maximum output shown on the production frontier surface, reflecting the structural and scale adjustment. ML-EFFECT index greater than 1 indicates an efficiency gain, while the opposite indicates an efficiency loss. The ML-TECH index indicates the movement of the production frontier surface, i.e., the additional growth rate of output for a given amount of inputs, reflecting process innovation and technological progress. ML-TECH index greater than 1 indicates the emergence of technological progress, while the opposite indicates technological regression.

\subsection{Variables and Data}

According to the measurement model of IGTFP and data availability, China's 29 provinces (excluding Hong Kong, Macao, Taiwan, Hainan and Tibet) are selected for this study. The research period is 1995-2017. All the basic data are obtained from the China Compendium of Statistics 1949-2008, the China Statistical Yearbook, the China Energy Statistical Yearbook and the statistical yearbooks of each province in the past years. The inputs and outputs in the model are described in detail below.

(1) Inputs

Capital, labor and energy are selected as inputs in the model to measure the IGTFP. First, capital input is measured using capital stock. Drawing on most of the literature, we adopt the perpetual inventory method to calculate the capital stock, which is calculated as $k_{t}=I_{t}+(1-\delta) k_{t-1}$. In this equation, $k_{t}$ and $k_{t-1}$ denote the capital stock in year $t$ and year $t-1$, respectively; $I_{t}$ denotes the investment in year $t$, expressed as the total fixed asset formation in each province; $\delta$ denotes the depreciation rate. The data of capital stock of each province from 1995 to 2008 used in this paper are from Shan [43], which is calculated in 1952 prices. For the capital stock data from 2009 to 2017, this paper estimates the capital stock of each province in this period (with 1952 as the base period) based on the total fixed asset formation and fixed asset investment price index of each province, and drawing on the depreciation rate of $10.96 \%$ proposed by Shan [43]. Among them, the total fixed asset formation and the price index of fixed asset investment are obtained from the statistical yearbooks of each province in previous years. Second, this paper selects the number of employees in each province from 1995 to 2017 to measure labor input, which is obtained from the labor statistics yearbook of each province in previous years. Third, the total energy consumption of each province is selected to measure energy input in this paper, and the data are obtained from the energy statistical yearbook of each province in previous years.

(2) Desired output

In this paper, the real GDP of each province in 1952 prices is selected to measure the desired output, which is obtained from the China Compendium of Statistics 1949-2008 and the statistical yearbooks of each province in previous years.

\section{(3) Undesirable outputs}

This paper considers two undesirable outputs when measuring IGTFP, environmental pollution and income disparity. For the environmental pollution indicator, due to data availability and the importance of addressing climate change, we choose carbon emissions from fossil fuel combustion as the pollutant emission indicator. This paper calculates the carbon emissions of each province during the period 1995-2017 based on the consumption of eight major fossil fuels (coal, coke, diesel, kerosene, gasoline, fuel oil, crude oil and 
natural gas) and the carbon emission factors of each fossil fuel. The relevant data was obtained from the China Energy Statistical Yearbook and energy statistical yearbooks of each province in previous years. In terms of income disparity, the Gini coefficient is the most common measure of income disparity, but data on Gini coefficients for China's provinces are missing. Since China has a typical urban-rural dual economy structure, the income inequality between urban and rural areas can reflect the overall income inequality in China to some extent. Therefore, this paper measures the income disparity by the ratio of per capita disposable income of urban residents to that of rural residents in each province. The larger the ratio is, the larger the income gap is and the less inclusive the economy is; conversely, the smaller the ratio is, the smaller the urban-rural income gap is, the fairer and more reasonable the income distribution is and the more inclusive the economic growth is. The data are obtained from the statistical yearbooks of each province in previous years. Descriptive statistics of inputs and outputs in the model are shown in Table 1.

Table 1. Descriptive statistical of inputs and outputs.

\begin{tabular}{ccccc}
\hline & $\begin{array}{c}\text { Standard } \\
\text { Deviation }\end{array}$ & Maximum & Minimum & Mean \\
\hline Labors (10,000) & 1613.81 & 6767 & 240.6 & 2510.11 \\
$\quad$ Capital stock (billion yuan) & 7928.63 & $47,559.02$ & 69.7 & 6027.44 \\
Energy consumption (million tons) & 7443.38 & 38,899 & 687.71 & 9855.99 \\
$\quad$ GDP (billion yuan) & 2487.42 & $14,844.47$ & 40.41 & 2217.70 \\
Carbon emissions (100,000 tons) & 2254.84 & $14,087.14$ & 1.60 & 2.83 \\
$\quad$ Ratio of per capita disposable & & 4.59 & & \\
income of urban residents to that of & 0.59 & & \\
$\quad$ rural residents & & & \\
\hline
\end{tabular}

\section{Results of Measuring IGTFP}

To compare the differences between IGTFP and traditional TFP in China, we first calculate traditional TFP (input factors include labor, capital and energy, and output only includes desired output) for China's provinces from 1995 to 2017 based on the M-index, and then estimate IGTFP for provinces in this period based on the ML-index. Next, we analyze the overall characteristics and regional characteristics of China's IGTFP.

\subsection{TFP, IGTFP and Economic Growth in China}

\subsubsection{Comparison of TFP and IGTFP}

Table 2 shows the TFP and IGTFP in China and their decomposition results in the whole research period and different stages. As shown in the sixth row of Table 2, from 1995 to 2017, the average annual growth rates of TFP and IGTFP in China were $2.5 \%$ and $1.84 \%$, respectively; those of the M-EFFECT and ML-EFFECT index decomposed from TFP and IGTFP were $-0.46 \%$ and $-0.2 \%$, respectively; those of the M-TECH and MLTECH index decomposed from them were $3 \%$ and $2.04 \%$, respectively. It can be seen that, firstly, although both TFP and IGTFP show positive growth trends, their average annual growth rates differ significantly, with the average annual growth rate of TFP being $0.66 \%$ higher than that of IGTFP. Secondly, the average annual growth rates of the M-EFFECT and ML-EFFECT indexes are negative, with a difference of $0.26 \%$ in their values. Finally, the average annual growth rates of the M-TECH and ML-TECH indexes are positive, but the former is much higher than the latter, and the difference between them is $0.96 \%$. In addition, Figure 1 describes the trend of the growth rates of China's IGTFP and TFP from 1995 to 2017. It can be found that before 2010, the growth rates of IGTFP were significantly different from those of TFP, and the growth rates of the former were generally smaller than those of the latter. After 2010, the gap between the growth rates of IGTFP and TFP narrowed significantly. In most years, the growth rates of IGTFP were smaller than those of TFP, while in 2013, 2014 and 2016, the growth rates of the former were greater than those of the latter. On the one hand, the implementation of low-carbon pilot policy, carbon trading 
pilot policy and other energy saving and emission reduction policies and measures in China has reduced the growth rate of China's carbon emissions and promoted the substantial growth of IGTFP. On the other hand, in recent years, China has attached great importance to income distribution and continuously deepened the reform of the income distribution system, which has also promoted the increase in IGTFP to a certain extent. These two reasons may explain the phenomenon that the gap between the growth rates of IGTFP and TFP narrowed after 2010 and the growth rates of IGTFP even surpassed those of TFP in some years. This finding is basically consistent with that of Chen and Zhang [44]. They suggested that the growth rates of green TFP were lower than those of traditional TFP before 2005, and exceeded those of traditional TFP after 2005. Since this paper examines the characteristics of IGTFP, its trend characteristics are similar to, but not fully consistent with, the trend characteristics of green TFP proposed by Chen and Zhang [44].

Table 2. TFP index and IGTFP index in China.

\begin{tabular}{ccccccc}
\hline & \multicolumn{2}{c}{ TFP Index and Its Decomposition } & \multicolumn{2}{c}{ IGTFP Index and Its Decomposition } \\
\cline { 2 - 6 } & TFP Index & $\begin{array}{c}\text { M-EFFECT } \\
\text { Index }\end{array}$ & $\begin{array}{c}\text { M-TECH } \\
\text { Index }\end{array}$ & $\begin{array}{c}\text { IGTFP } \\
\text { Index }\end{array}$ & $\begin{array}{c}\text { ML-EFFECT } \\
\text { Index }\end{array}$ & $\begin{array}{c}\text { ML-TECH } \\
\text { Index }\end{array}$ \\
\hline 1995-2003 (Stage I) & 1.0321 & 0.9990 & 1.0332 & 1.0196 & 1.0013 & 1.0179 \\
2003-2013 (Stage II) & 1.0218 & 0.9890 & 1.0333 & 1.0179 & 0.9949 & 1.0233 \\
2013-2017 (Stage III) & 1.0190 & 1.0039 & 1.0155 & 1.0171 & 0.9993 & 1.0183 \\
1995-2017 & 1.0250 & 0.9954 & 1.0300 & 1.0184 & 0.9980 & 1.0204 \\
\hline
\end{tabular}

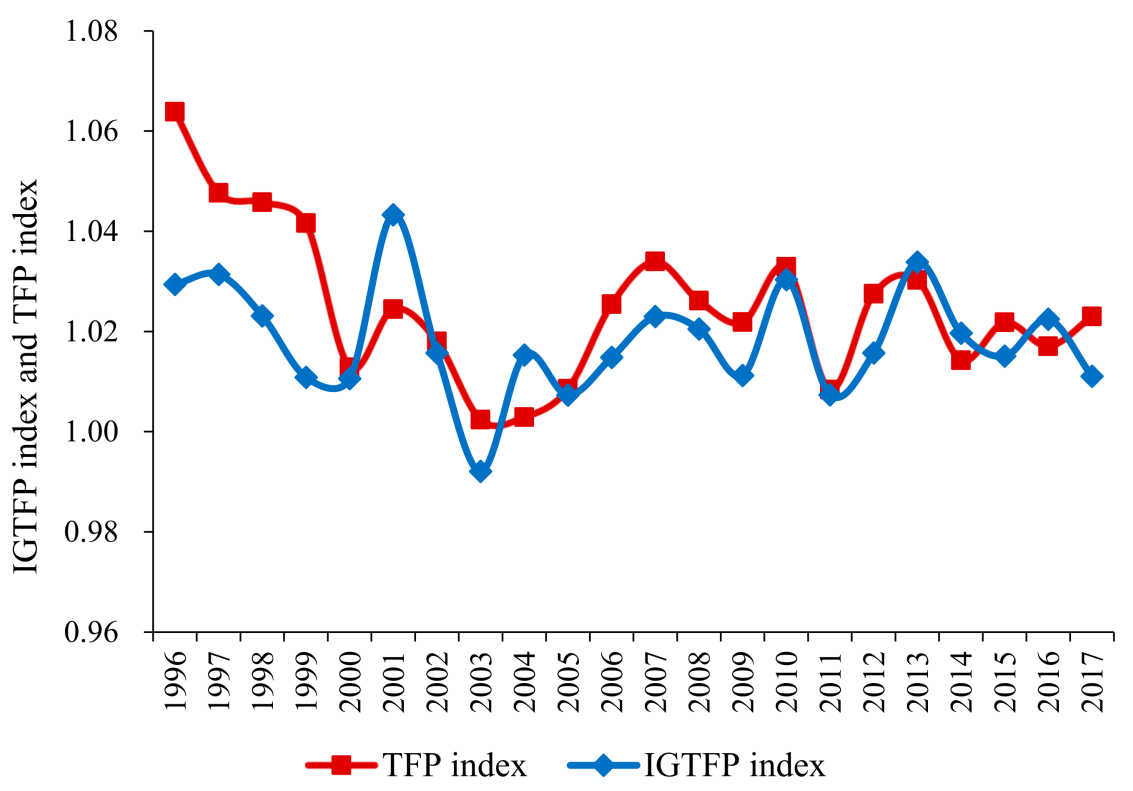

Figure 1. Changing trend of IGTFP index and TFP index in China from 1995-2017.

It is worth noting that the average annual growth rate of IGTFP in China showed several distinct inflection points between 1995 and 2017. First, the average annual growth rate of IGTFP declined significantly in 2003. This may be highly correlated with the SARS outbreak in China in 2003. Since SARS hit China's economy mainly in 2003, the average annual growth rate of China's IGTFP increased significantly in 2004. Second, the average annual growth rate of IGTFP showed a continuous downward trend in 2008-2009. This phenomenon may have been caused by the global financial crisis in 2008. Subsequently, the increase in the average annual growth rate of IGTFP in 2010 may be attributed to the stimulus of China's quadrillion plan and a series of subsequent policies after the financial crisis. Third, the decline in the average annual growth rate of IGTFP in 2011 may be related to the transition from faster growth in China's economy under policy stimulus to 
stable growth under structural adjustment. Finally, from 2013 to 2017, the average annual growth rate of IGTFP shows a fluctuating downward trend. This may be attributed to the slowdown in China's economic growth as well as the growing problems of environmental pollution and polarization between the rich and the poor.

The above results suggest that, first, China's real productivity may have been overestimated during the period 1995-2017. For a long time, traditional TFP, which did not include undesirable outputs such as environmental pollution and income disparity, was regarded as China's real TFP. However, increasing environmental pollution and widening of the wealth gap are real problems that China must face and solve in the process of economic growth. Therefore, compared with traditional TFP, IGTFP takes into account both desired outputs and undesirable outputs that have a significant negative impact on the quality of economic growth, and it is a more accurate measure of China's real TFP. The level of real TFP determines the quality of a country's economic growth to a certain extent. The relatively small value of IGTFP calculated in this paper indicates that although China's economy is growing, the quality of economic growth is low and problems such as ecological and environmental degradation and income inequity are still relatively prominent. Therefore, China has a long way to go to achieve inclusive green economic growth. Second, technological progress has a significant positive impact on both TFP and IGTFP. This indicates that technological progress is the main source of driving force for improving TFP and IGTFP. Third, during the research period, efficiency loss had a certain degree of inhibitory effect on improving TFP and IGTFP. TFP is essentially a kind of resource allocation efficiency. Since the reform and opening up, China has devoted itself to increasing the rate of technological progress but neglected the optimal allocation of resources, thus leading to a lower ML-EFFECT index. As far as the calculation method is concerned, the IGTFP index is the product of the ML-EFFECT index and the ML-TECH index. Therefore, technological progress should be ensured along with reasonable optimization of resource allocation, so as to achieve inclusive green economic growth.

\subsubsection{IGTFP and Economic Growth}

Table 2 demonstrates the stage-by-stage change characteristics of China's IGTFP and its decomposed ML-EFFECT index and ML-TECH index. To facilitate the analysis, we use Figure 2 to depict the changing trend of IGTFP, ML-EFFECT index and ML-TECH index in detail. As can be seen from Table 2 and Figure 2, overall, the average annual growth rate of IGTFP tends to decline from the first stage to the second stage, and then to the third stage, but the decline in the latter stage slows down. The annual average growth rate of the ML-EFFECT index starts to increase in the third stage after decreasing from the first stage to the second stage, but after the increase, its annual average growth rate is still negative. The average annual growth rate of the ML-TECH index shows an increasing trend from the first to the second stage, but starts to decrease in the third stage, and after the decrease, its average annual growth rate is still positive.

In terms of specific stages, the average annual growth rate of IGTFP decreases from $1.96 \%$ in the first stage to $1.79 \%$ in the second stage, that of the ML-EFFECT index decreases from $0.13 \%$ to $-0.51 \%$, and that of the ML-TECH index increases from $1.79 \%$ to $2.33 \%$. This suggests that the decline in the average annual growth rate of the IGTFP is due to the fact that the negative effect of efficiency loss on the IGTFP is greater than the positive effect of technological progress on it. In fact, there are three possible reasons for this phenomenon. First, before the beginning of the first stage, China's reform and opening-up policy led to rapid economic growth and a rapid increase in IGTFP. After entering the second stage, supply-side quality and structural problems gradually came to the fore. The long-term accumulation of these problems led the economy to suffer from a series of growth problems such as overcapacity, the structural mismatch between supply and demand, and distorted factor allocation. This may be one of the reasons why the average annual growth rate of IGTFP in the second stage decreases to a certain extent compared with the first stage. Second, the IGTFP incorporates environmental pollution as an undesirable output into the 
model. With the rapid development of China's economy, economic growth has become more and more speed-oriented and less quality-oriented. Economic development in the second stage has been at the expense of the ecological environment, and its damage to resources and environment has far exceeded expectations, leading to increasingly serious environmental pollution problems. This is an important reason for the declining average annual growth rate of IGTFP. Finally, the IGTFP also introduces income disparity as another undesirable output into the model. At the beginning of reform and opening up, China proposed the policy of "letting some people and some regions get rich first". After years of reform and development, people's living standard has been improving, but the problem of the wealth gap has also become increasingly serious. Especially since the second stage, not only has the income gap between urban and rural residents widened but also the phenomenon of income inequality within cities and rural areas has become more serious. The efficiency loss caused by the excessive income disparity is the third reason for the decline in the average annual growth rate of IGTFP in the second stage.

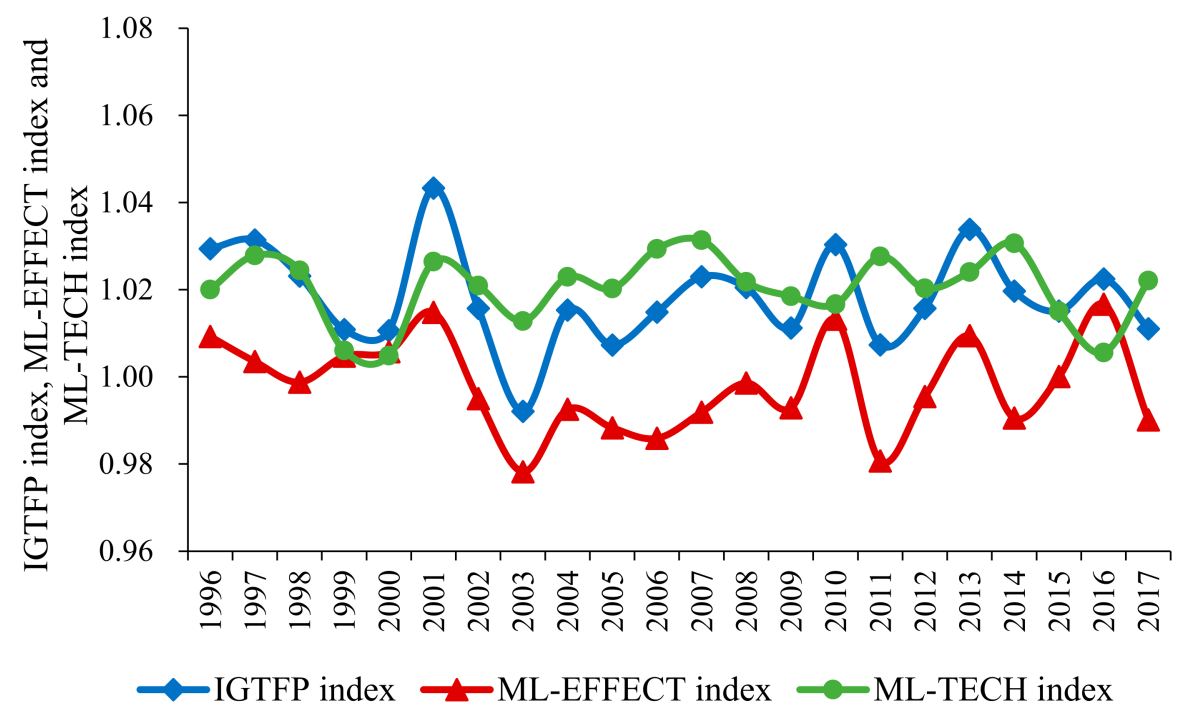

Figure 2. Changing trend of IGTFP index, ML-EFFECT index and ML-TECH index in China from 1995-2017.

After experiencing a decline from the first stage to the second stage, the average annual growth rate of the IGTFP still shows a downward trend in the third stage, but the decline slows down, only from $1.79 \%$ in the second stage to $1.71 \%$ in the third stage. Meanwhile, the average annual growth rate of the ML-TECH index decreases from $2.33 \%$ in the second stage to $1.83 \%$ in the third stage, while that of the ML-EFFECT index increases from $-0.51 \%$ to $-0.07 \%$. It can be found that although the growth rate of the ML-EFFECT index in the third stage has increased significantly, it still shows a negative growth. The continued decline in resource allocation efficiency and the slowdown in the rate of technological progress may be the main reasons why the average annual growth rate of IGTFP is still on a downward trend. In addition, when the economy experienced a structural imbalance between supply and demand, the government put forward a supply-side structural reform policy. This policy not only focuses on optimizing resource allocation and promoting structural adjustment but also requires adhering to green development and coordinated development in the economic development, focusing on environmental protection and narrowing the gap between the rich and the poor. This may be an important reason for the significant slowdown in the decline of the average annual growth rate of IGTFP from the second to the third stage. 


\subsection{Regional Characteristics of IGTFP in China \\ 4.2.1. IGTFP in Three Regions}

To analyze the regional characteristics of China's IGTFP, this paper divides the country into three regions based on the economic development and geographical location, namely eastern, central and western regions (The eastern region includes Liaoning, Beijing, Hebei, Tianjin, Shandong, Jiangsu, Shanghai, Zhejiang, Fujian, Guangdong; the central region includes Heilongjiang, Jilin, Shanxi, Henan, Hubei, Anhui, Hunan, Jiangxi; the western region includes Xinjiang, Gansu, Inner Mongolia, Qinghai, Ningxia, Shaanxi, Sichuan, Guizhou, Yunnan, Guangxi). Table 3 shows the IGTFP index, ML-TECH index and ML-EFFECT index for the three regions in China from 1995 to 2017. In order to fully analyze the change characteristics of IGTFP, we also give the TFP index of these three regions in Table 3. Figure 3 further depicts the changing trend of IGTFP in the three regions during the research period.

Table 3. TFP index, IGTFP index, ML-EFFECT index and ML-TECH index in three major regions of China from $1995-2017$.

\begin{tabular}{ccccc}
\hline & TFP Index & IGTFP Index & ML-EFFECT Index & ML-TECH Index \\
\hline Eastern Region & 1.0508 & 1.0364 & 1.0008 & 1.0359 \\
Central Region & 1.0305 & 1.0127 & 0.9978 & 1.0149 \\
Western Region & 0.9966 & 1.0061 & 0.9956 & 1.0104 \\
\hline
\end{tabular}

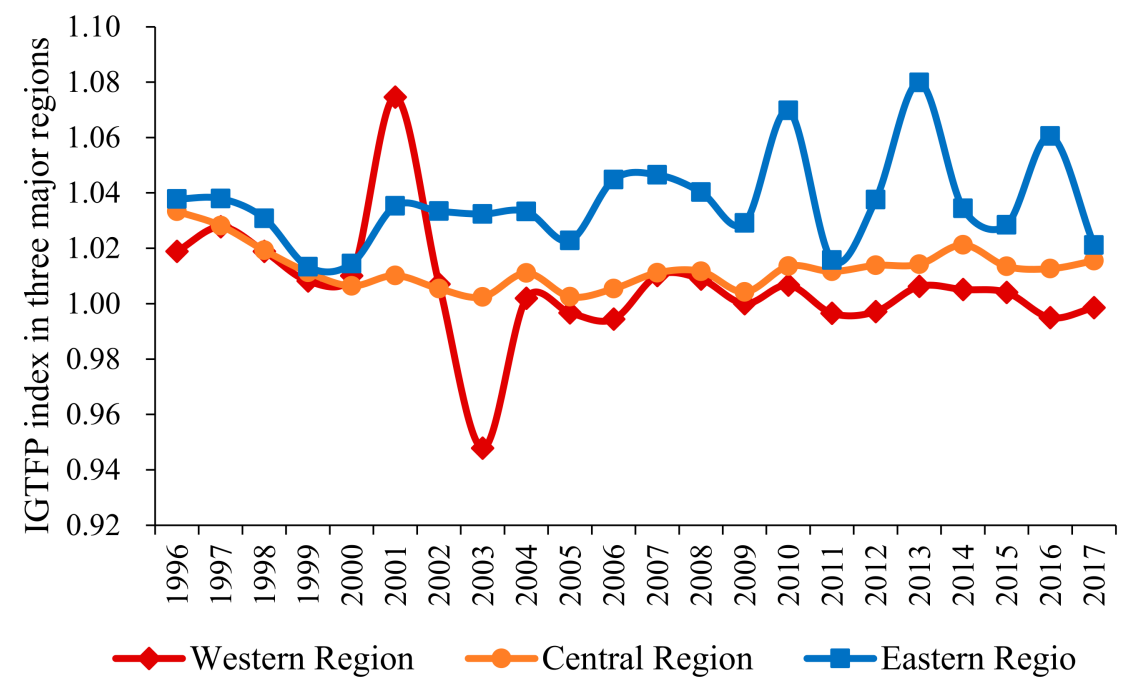

Figure 3. Changing trend of IGTFP index in three major regions of China from 1995-2017.

As can be seen from Table 3, firstly, the IGTFP in the three regions achieve positive growth during the research period. Among them, the eastern region has the fastest growth of IGTFP, and its average annual growth rate reaches $3.64 \%$, which is significantly larger than the $1.27 \%$ in the central region and $0.61 \%$ in the western region. It can be found that the average annual growth rate of IGTFP shows a stepped downward trend from east to west. From Table 3 we can see that the average annual growth rate of traditional TFP in China also shows the spatial distribution characteristics of "high in the eastern region, middle in the central region, and low in the western region". It can be found that the distribution characteristics of the growth rates of TFP and IGTFP are very similar. In terms of calculation methods, the difference between traditional TFP and IGTFP is that two undesirable outputs, environmental pollution and income disparity, are introduced when measuring IGTFP. Therefore, the distribution characteristics of traditional TFP largely determine those of IGTFP. However, due to the differences in environmental and wealth disparities among the three regions, the regional characteristics of IGTFP, which takes into account pollution emissions and income disparities, are not entirely consistent with that 
of traditional TFP. For example, the growth rate of IGTFP in the eastern region is $2.37 \%$ higher than that in the central region, while the growth rate of TFP in the eastern region is $2.03 \%$ higher than that in the central region. This suggests that introducing environmental and income inequality factors increases the gap between the real TFP growth rates in the eastern and central regions. According to the calculation results of this paper, from 1995 to 2017, the average per capita carbon emissions in the eastern and central regions were 7.05 and 5.27 tons per person, respectively, while the average values of the ratio of urban and rural residents' income were 2.38 and 2.61 , respectively. It could be inferred that it is likely that the dampening effect of income gap on the growth rate of IGTFP is greater than that of carbon emissions, which in turn leads to a significantly larger decline in the growth rate of IGTFP in the central region than in the eastern region after introducing environmental pollution and income disparity. This further suggests that the phenomenon that the growth rate of IGTFP in the eastern region is higher than that in the central region, is not only because the former has a higher TFP growth rate than the latter but also because the income gap in the central region is larger than that in the eastern region.

Next, the average annual growth rates of IGTFP in the eastern, central and western regions are $3.59 \%, 1.49 \%$ and $1.04 \%$, respectively. This indicates that technological progress in all regions has contributed positively to improving the IGTFP during the research period. However, there are differences in the extent of this driving effect in different regions. Among them, economic growth in the eastern region is driven the most by technological progress, followed by the central region, and the western region receives the least boost. Finally, in terms of efficiency change, the average annual growth rate of the ML-EFFECT index in the eastern region is $0.08 \%$, while those of the ML-EFFECT index in the central and western regions are $-0.22 \%$ and $-0.44 \%$, respectively. This indicates that improving the resource allocation efficiency in the eastern region has a positive driving effect on IGTFP growth during the research period; both the central and western regions show different degrees of efficiency loss, and the IGTFP growth in the western region is most inhibited by its efficiency loss.

Figure 3 shows that the ML-index of the eastern region is greater than one throughout the research period, and the ML-index is greater than that of the central and western regions except for a few years (2001). This indicates that the IGTFP in the eastern region has a stable growth trend, and its growth rate is overall higher than that of the central and western regions. By stages, from 1996 to 2000, the ML-indexes of the three regions show a decreasing trend in general, but the values are all greater than one. Among them, the decreasing trend is most significant in the central region, followed by the eastern region and that in the western region is relatively small. This implies that the IGTFP in all three regions maintains positive growth during this period, but its growth rate slows down, especially in the central and eastern regions. The reason for this might be that, with the accelerated pace of reform and opening up from the late 20th century to the early 21st century, the problem of speed over quality in economic development emerged. The problem is particularly evident in the eastern and central regions. It not only leads to serious damage to the ecological environment but also gradually widens the gap between the rich and the poor, thus inhibiting the growth rate of IGTFP. After 2000, the ML-indexes of both the eastern and central regions show a fluctuating upward trend, but that of the western region shows a fluctuating downward trend. Specifically, the ML-index in the eastern region increases from 1.0145 in 2000 to 1.0212 in 2017, and the central region increases from 1.0065 to 1.0155 . This means that the IGTFP in both the eastern and central regions maintains positive growth from 2000 to 2017, and the growth rate accelerates. The reason for this phenomenon may be that the government attached great importance to green and sustainable development and introduced a series of policies and measures to protect the ecological environment and limit pollutant emissions, which promoted the rapid growth of IGTFP. Differently, the ML-index of the western region decreases from 1.0101 in 2000 to 0.9986 in 2017. This may be because, on the one hand, the implementation of the western development strategy led to the economic development of the western region, but it also increased the demand for 
resources in the region, which in turn caused ecological damage as well as the deterioration of the natural environment; on the other hand, the western development strategy may have widened the urban-rural income gap in the western region $[45,46]$, thus leading to a decline in IGTFP.

\subsubsection{IGTFP in Provinces}

Figure $4 \mathrm{a}-\mathrm{d}$ depict the average changes in the TFP index, IGTFP index, ML-EFFECT index and ML-TECH index for each province in China over the period 1995-2017, respectively. From Figure $4 b$, it can be seen that the IGTFP index is greater than one in all 28 provinces, except Yunnan. That is, all of these provinces have experienced positive growth in IGTFP. Among them, eastern coastal provinces and cities such as Beijing, Tianjin, Shandong, Jiangsu and Shanghai have the fastest growth in IGTFP, with an average annual growth rate of more than 3\%; northwestern provinces and regions such as Xinjiang, Qinghai and Gansu, and northeastern provinces such as Heilongjiang and Jilin have slower growth, with an average annual growth rate of less than $1 \%$. Figure $4 \mathrm{c}$ depicts the characteristics of the differences in the average annual growth rate of the ML-EFFECT index across provinces during the study period. It can be found that the provinces with the positive average annual growth rate of the ML-EFFECT index are Beijing, Tianjin, Shanghai, Jiangsu, Anhui, Ningxia, Sichuan, Chongqing and Guangdong. Among them, Beijing has the fastest growth rate, with an average annual growth rate of $1.52 \%$, and Guangdong has the slowest growth rate, with an average annual growth rate of $0.03 \%$. Except for the above eight provinces and cities, the rest of the provinces experience negative growth in the ML-EFFECT index, with the largest negative growth being in Xinjiang, which has an average annual growth rate of $-1.34 \%$. This indicates that most provinces experienced efficiency losses during the study period. As shown in Figure $4 d$, the average annual growth rate of the ML-TECH index is positive in all provinces and cities except Yunnan. Among them, Beijing, Tianjin, Shanghai and other eastern coastal provinces and cities have the fastest growth in technological progress, while northeastern provinces such as Heilongjiang and Jilin and southwestern provinces and cities such as Guangxi and Chongqing have slower growth. This implies that technological progress existed in most provinces during the research period, and the eastern coastal provinces had a faster rate of technological progress than the central and western provinces. The reason for this may be that the eastern coastal regions have a strong economic base and innovation capacity, and, thus, their technological progress is significantly faster than other regions. Comparing Figure $4 c, d$, the average annual growth rate of the ML-TECH index in each province is generally higher than that of the ML-EFFECT index. According to this analysis, although some provinces in the eastern region experienced efficiency losses, the growth effect of their technological progress was much greater than the negative effect of efficiency changes, which led to the rapid growth of IGTFP; similarly, even though some western provinces experienced efficiency gains, the speed of their technological progress was lower, and, thus, the growth rate of IGTFP is relatively slow. This may be the reason for the rapid growth of IGTFP in the eastern coastal region and the relatively slower growth in the northwest and northeast. 


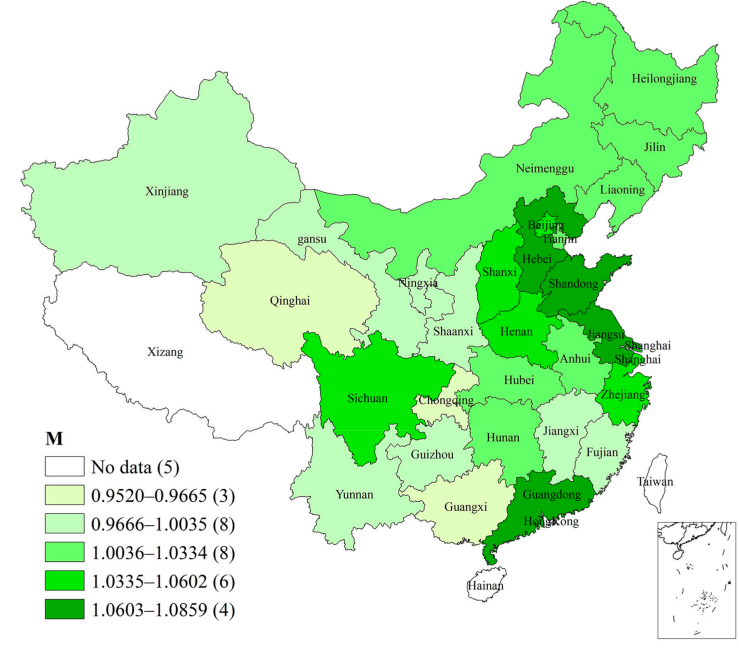

(a)

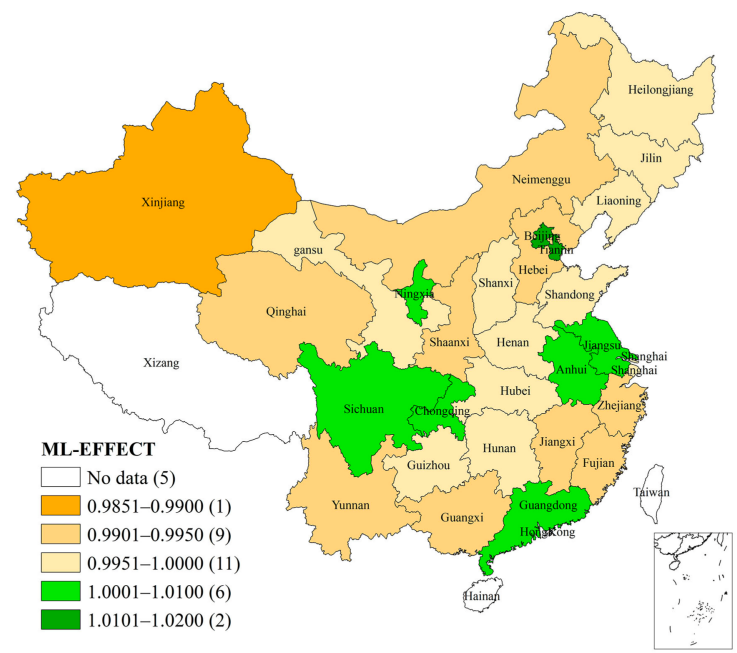

(c)

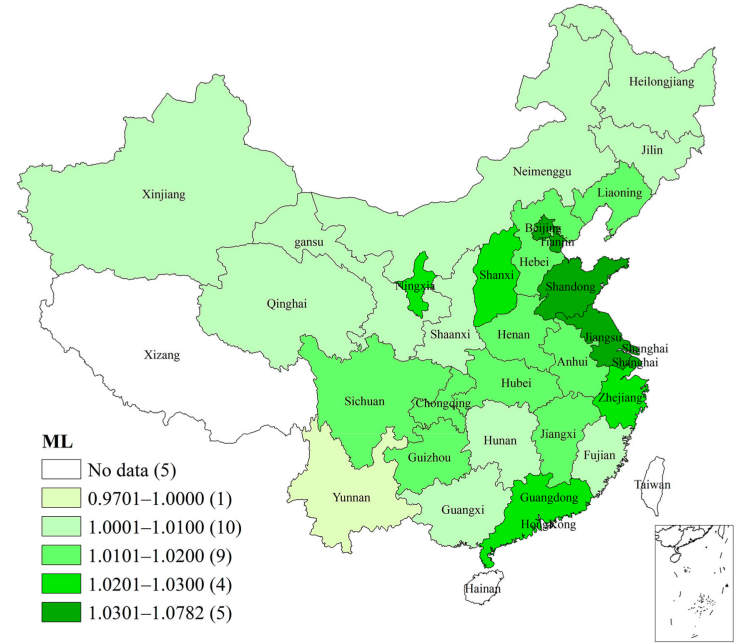

(b)

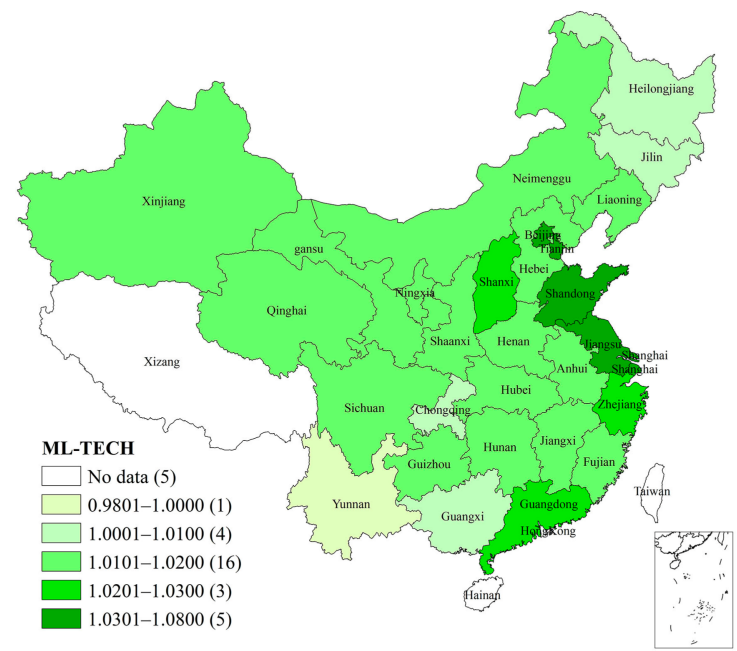

(d)

Figure 4. TFP index, IGTFP index, ML-EFFECT index and ML-TECH index of China's province from 1995-2017. (a) TFP index; (b) IGTFP index; (c) ML-EFFECT index; (d) ML-TECH index.

The above analysis shows that the provinces with high average annual growth rates of IGTFP in China are concentrated in the eastern coastal region, and those with relatively low average annual growth rates are mainly located in the northeast, northwest and southwest regions. This is basically consistent with the spatial distribution characteristics of the average annual growth rate of TFP in China's provinces shown in Figure 4a. The slight differences between the distribution characteristics of the IGTFP index and TFP index may be caused by the differences in carbon emissions and income disparities among provinces. For example, the growth rate of TFP of Hebei is at a high level, while the growth rate of IGTFP of this province is at a medium level. Introducing the environmental factors reduces the growth rate of Hebei's real TFP, which is caused by its high carbon emissions and per capita carbon emissions. The calculation results of this paper show that the average carbon emissions of Hebei reached 586 million tons during 1995-2017, making it the second largest carbon emitting province in China; its per capita carbon emissions were 8.28 tons per person, ranking eighth among all provinces in terms of per capita carbon emissions. Similarly, introducing the environmental and income distribution factors also lowered the ranking of real TFP growth rate of Guangdong. According to the calculation results of this paper, in 1995-2017, the average value of the ratio of urban and rural residents' income in 
Guangdong was 2.86, which was at the middle level of the country, thus reducing its real TFP growth rate.

Overall, the above results indicate that the environmental efficiency of economic growth in the eastern region is higher and more inclusive, while that in the central and western regions is lower and less inclusive. First, the reasons for the higher environmental efficiency in the eastern region than central and western regions are as follows. Due to its strong economic base, the eastern region is able to maintain economic growth and environmental protection at the same time; in contrast, most provinces in the central and western regions have a weak economic base, and some provinces still maintain an extensive development mode, making it difficult to balance economic growth and environmental protection at the same time. Meanwhile, the environmental efficiency of the western region is lower compared to the central region. This is due to the fact that the western region not only has a weak economic base and fragile ecology but also has taken over some heavier polluting industries transferred from developed regions so as to promote economic development, which has incidentally caused environmental pollution and ecological imbalance. Second, economic growth in the eastern region is more inclusive, while the central and western regions face the challenge of widening urban-rural income disparity. The urban-rural income gap in the eastern region is smaller than that in the central and western regions, and the smaller gap between the rich and the poor can greatly motivate workers, thus helping to promote the IGTFP growth. As a result, the eastern region has achieved a virtuous cycle of income gap reduction and IGTFP growth. In contrast, the central and western regions face the serious challenge of a persistently widening gap between the rich and the poor. In conclusion, China not only needs to increase environmental protection efforts in all regions, reduce pollution emissions and improve resource utilization efficiency, but also should further deepen the reform of the income distribution system, narrow the income gap between urban and rural areas, and promote coordinated development in all regions. This is an inevitable requirement for China to achieve inclusive green economic growth.

\section{Impact of Economic Structure Optimization on IGTFP \\ 5.1. Estimation Method and Variables}

To investigate whether economic structural optimization in the supply-side structural reform enhances the IGTFP in China, this paper selects five indicators of reflecting structural optimization to examine the effects of economic structural optimization on IGTFP. The five indicators are industrial structure, factor structure, labor structure, energy structure and urban-rural structure. Meanwhile, this paper also selects a series of factors that may affect IGTFP as control variables introduced into the model, including variables reflecting the overall economic situation and variables representing technological innovation. The definitions of each variable and related data sources are shown in Table 4.

Table 4. Definitions of variables in the model and related data sources.

\begin{tabular}{|c|c|c|}
\hline Category of Variables & Variables & Definitions and Related Data Sources \\
\hline $\begin{array}{c}\text { Structural optimization in } \\
\text { supply-side structural reform }\end{array}$ & IS (Industrial structure) & $\begin{array}{l}\text { IS is measured by the proportion of the value } \\
\text { added of the secondary industry to GDP in each } \\
\text { region, the data are obtained from the statistical } \\
\text { bulletins on national economic and social } \\
\text { development and statistical yearbooks of each } \\
\text { province in previous years. }\end{array}$ \\
\hline & FS (Factor structure) & $\begin{array}{l}\text { FS refers to the differences in factor endowments } \\
\text { by region, measured as the ratio of capital stock to } \\
\text { the number of employees, i.e., capital per laborer; } \\
\text { data are obtained from Shan and the statistical } \\
\text { yearbooks of each province in previous years [ } 43] \text {. }\end{array}$ \\
\hline
\end{tabular}


Table 4. Cont.

\begin{tabular}{|c|c|c|}
\hline Category of Variables & Variables & Definitions and Related Data Sources \\
\hline & LS (Labor structure) & $\begin{array}{l}\text { LS is measured by the proportion of workers with } \\
\text { college education or above; data were obtained } \\
\text { from the sample surveys of population change in } \\
\text { previous years (1995-1999, 2001-2005) and the } \\
\text { information of labor force surveys in previous } \\
\text { years (2006-2009, 2011-2017), the data of } 2000 \text { and } \\
2010 \text { are obtained from the fifth and sixth national } \\
\text { census, respectively. }\end{array}$ \\
\hline & ES (Energy structure) & $\begin{array}{l}\text { ES is measured by the ratio of the sum of coal and } \\
\text { crude oil consumption to total energy } \\
\text { consumption, the data are obtained from the } \\
\text { energy statistical yearbooks of each province in } \\
\text { previous years. }\end{array}$ \\
\hline & URS (Urban-rural structure) & $\begin{array}{l}\text { URS refers to the urbanization rate, which is } \\
\text { measured by the proportion of urban population } \\
\text { to the total population of each province in each } \\
\text { year, and the data are obtained from the statistical } \\
\text { yearbooks of each province in previous years. }\end{array}$ \\
\hline Overall economic situation & PGDP (GDP per capita) & $\begin{array}{l}\text { PGDP is measured by the regional GDP per capita } \\
\text { at constant prices in 1952; the data are obtained } \\
\text { from the China Compendium of Statistics } \\
\text { 1949-2008 and the statistical yearbooks of each } \\
\text { province in previous years. }\end{array}$ \\
\hline \multirow{3}{*}{ Technology innovation } & OPEN (Opening-up degree) & $\begin{array}{l}\text { OPEN is measured by the proportion of the total } \\
\text { regional import and export in the GDP of the } \\
\text { region, the data are obtained from the statistical } \\
\text { yearbook of each province in previous years, } \\
\text { China's economic and social big data research } \\
\text { platform and the official website of the People's } \\
\text { Bank of China. }\end{array}$ \\
\hline & RD (Proportion of R\&D input) & $\begin{array}{c}\text { RD is measured by the share of R\&D expenditure } \\
\text { in GDP of each region, the data are obtained from } \\
\text { the China Statistical Yearbook on Science and } \\
\text { Technology in previous years. }\end{array}$ \\
\hline & $\begin{array}{l}\text { PATENT (Number of patent } \\
\text { applications granted) }\end{array}$ & $\begin{array}{l}\text { PATENT refers to the number of patent } \\
\text { applications granted in each region, which is an } \\
\text { important indicator to measure the level of } \\
\text { technological innovation, and the data are } \\
\text { obtained from China Statistical Yearbook on } \\
\text { Science and Technology in previous years. }\end{array}$ \\
\hline
\end{tabular}

The reasons for selecting control variables in the panel data model are as follows. First, we use the level of economic development and the degree of opening up as the control variables reflecting the overall economic situation of a region. The level of economic development of a region not only affects the local environmental quality, but also is closely related to the local income gap. That is, the level of economic development may affect the IGTFP. Meanwhile, the impact of a region's opening-up degree on its IGTFP cannot be ignored. A higher opening-up degree is beneficial for the region to learn from foreign advanced experience and technology, thus improving productivity; however, it may also bring environmental pollution to the region, thereby hindering the improvement of IGTFP. Therefore, we introduce the level of economic development and the degree of opening up as control variables into the model. Second, we introduce the proportion of R\&D input and the number of patent applications granted as control variables reflecting the level of regional technological innovation into the model. On the one hand, technological innovation is the fundamental driving force for green development, which is conducive to improving factor utilization efficiency and promoting green sustainable development; on 
the other hand, technological innovation may also affect income distribution [47], thereby affecting the IGTFP.

Based on the variables defined in Table 4, the following panel data model to investigate the impact of structural optimization on IGTFP is constructed in this paper

$$
\begin{gathered}
\operatorname{IGTFP}_{i t}=\beta_{0}+\beta_{1} I S_{i t}+\beta_{2} \text { FS }_{i t}+\beta_{3} L S_{i t}+\beta_{4} E S_{i t}+\beta_{5} U R S_{i t}+\beta_{6} P G D P_{i t} \\
+\beta_{7} O P E N_{i t}+\beta_{8} R D_{i t}+\beta_{9} P_{A T E N T} T_{i t}+u_{i}+\lambda_{t}+\varepsilon_{i t}
\end{gathered}
$$

where $t$ is time and $i$ denotes province; the core explanatory variables IS, FS, LS, ES and $U R S$ refer to the five structural optimization indicators, industrial structure, factor structure, labor structure, energy structure and urban-rural structure, respectively; PGDP, OPEN, $R D$ and PATENT are control variables; $\beta_{0}$ refers to the intercept term, $\beta_{1}, \beta_{2}, \beta_{3}, \ldots \ldots, \beta_{9}$ denote the coefficients of explanatory variables; $u_{i}$ is individual fixed effects, $\lambda_{t}$ denotes time fixed effects and $\varepsilon_{i t}$ is the random disturbance term.

\subsection{Estimation Results}

Based on the results of the Hausman test, the fixed effects model should be selected for estimation in this paper. The estimation results using the two-way fixed effects model are reported in Table 5.

Table 5. Estimation results of the two-way fixed effects model.

\begin{tabular}{ccc}
\hline Variables & Meanings of Variables & $\mathbf{( 1 )}$ \\
\hline IS & Industrial structure & $-2.009^{* * *}$ \\
FS & Factor structure & $(0.359)$ \\
& & $0.038^{* * *}$ \\
LS & Labor structure & $(0.011)$ \\
& & $0.041^{* * *}$ \\
ES & Energy structure & $(0.006)$ \\
& & $-0.041^{* * *}$ \\
URS & Urban-rural structure & $(0.017)$ \\
& & 0.002 \\
PGDP & GDP per capita & $(0.002)$ \\
& & $1.203^{* * *}$ \\
OPEN & Opening-up degree & $(0.169)$ \\
& & $-0.644^{* * *}$ \\
RD & Proportion of R\&D input & $(0.114)$ \\
& & $0.370^{* * *}$ \\
PATENT & Number of patent applications granted & $(0.048)$ \\
& & $0.019^{* * *}$ \\
_cons & & $(0.006)$ \\
& & $-7.024^{* * *}$ \\
Hausman & & $(1.137)$ \\
$p$-value & & 27.44 \\
Obs. & & 0.0022 \\
R-squared & & 667 \\
& & 0.558 \\
\hline
\end{tabular}

Note: Standard errors are in parenthesis. ${ }^{* *} p<0.01,{ }^{* *} p<0.05,{ }^{*} p<0.1$.

The estimation results show that in the core explanatory variables, the coefficient of industrial structure, $I S$, is significantly negative. In other words, there is a significant negative correlation between industrial structure and IGTFP. The reason for this is that the industrial structure of China at this stage is dominated by manufacturing industries. The manufacturing industry, especially the low-end manufacturing industry, on the one hand, mainly relies on a large amount of resource inputs to achieve growth, which causes damage to resources and the environment, and, on the other hand, has relatively slow technological progress and relatively low technological level. Therefore, the increase in the proportion of the manufacturing industry will lead to a decrease in IGTFP. This result 
is consistent with the findings of existing studies such as Zhang and Tan who found a significant negative relationship between industrial structure (measured by the share of value added in the secondary sector in GDP) and green TFP [35], and Lu et al. who suggested that industrial structure rationalization had a significant contribution to the improvement in green TFP [26].

Factor structure FS has a significant positive impact on IGTFP. This is because the more capital stock there is available per unit of labor, the faster the growth of IGTFP. This result is in accord with Tao et al., who suggested that the capital-labor ratio had a significant positive effect on green TFP in China [34]. Labor structure $L S$ also has a significant positive impact on IGTFP. The higher the education level of the laborers means the stronger their learning ability and the easier it is to master the complex technology. This will increase per capita labor productivity, resulting in higher IGTFP. Energy structure, ES, shows a significant negative correlation with IGTFP. Since the ratio of the sum of coal and crude oil consumption to total energy consumption is chosen to measure energy structure indicator in this paper, this result suggests that the IGTFP will decrease with the increase in fossil energy consumption with high pollution such as coal and crude oil. This also suggests that promoting clean substitution of high-pollution fossil energy and promoting energy structure transformation are beneficial to the growth of IGTFP. Urban-rural structure, URS, has a positive impact on IGTFP. This may be because the increase in the urbanization rate helps to reduce the economic gap between urban and rural areas. This finding is basically consistent with the findings of previous studies, such as Li et al., who found that urbanization positively affected green China's TFP [32].

In addition, this paper further analyzes the estimation results based on the definition of each structural optimization indicator. First, the industrial structure is represented by the proportion of the value added of secondary industry to GDP in each region. For a long time, the proportion of emerging industries in China's industrial structure was relatively low, and the manufacturing industry was still at the middle and low-end level. Therefore, a lower share of low-end manufacturing industries and a higher share of emerging industries indicate the optimization of the industrial structure. Similarly, the increase in the proportion of highly educated workers means the optimization of labor structure, the increase in capital stock per unit of labor represents the optimization of factor structure, the decrease in the proportion of high-pollution fossil energy consumption indicates the optimization of energy structure and the increase in the urbanization rate means the optimization of urban-rural structure. Based on the above analysis, the increase in three indicators representing labor structure, factor structure and urban-rural structure, and the decrease in two indicators representing industrial structure and energy structure indicate economic structure optimization in the supply-side structural reform. The estimation results show that labor structure, factor structure and urban-rural structure are positively correlated with IGTFP, while industrial structure and energy structure are negatively correlated with IGTFP. This implies that economic structural optimization driven by supply-side structural reform will improve the IGTFP.

In terms of control variables, GDP per capita (PGDP) is positively correlated with the IGTFP. Economic development level is related to the environmental quality. The higher the economic development level, the higher the demand for the environment, and thus the better the harmony between economic development and environment [48]. This may be the reason why economic development level has a positive effect on IGTFP. Opening-up degree (OPEN) has a negative impact on the IGTFP. In general, the higher the opening-up degree of the region, the better the foreign trade and economic and technological exchange policies, and, accordingly, the faster the growth in regional productivity. The finding of this paper is not consistent with this expectation, and the reasons for this may be twofold. On the one hand, the development of international trade makes it easier for developed countries to transfer pollution-intensive industries to China, thus exacerbating domestic environmental pollution and leading to a decline in IGTFP; on the other hand, increased openness will lead to faster economic growth in more developed regions, which may further widen the 
income gap and thus reduce IGTFP. This finding is basically consistent with the findings of existing studies, such as Liu and Xin who suggested that foreign trade may have a negative impact on green TFP [33], and Li et al. who found that a high level of foreign openness would lead to a decrease in environmental TFP [48]. In addition, both the proportion of R\&D input (RD) and the number of patent applications granted (PATENT) have significant positive effects on IGTFP. The results in Section 4 show that technological progress is an important driving factor for IGTFP growth. A larger proportion of R\&D expenditures and a higher number of patent applications imply greater technological progress, which in turn improves IGTFP. This result is basically consistent with the view of Zhang and Tan [35].

\subsection{Robustness Tests}

\subsubsection{Robustness Test by Adjusting Sample Period}

In the benchmark regression model of Section 5.2, this paper uses data from 1995 to 2017. In November 2015, China first formally proposed the supply-side structural reform. Subsequently, supply-side reform programs were introduced in succession in each province. In order to avoid the potential impact of the formulation and implementation of supply-side reform programs in different provinces on IGTFP and ensure the robustness of the estimation results, this paper adjusts the sample period to 1995-2015 and re-estimates it using the two-way fixed effects model. The results are shown in column (1) of Table 6 . The estimation results show that among the core explanatory variables representing structural optimization in supply-side structural reform, both industrial structure IS and energy structure $E S$ have significant negative impacts on the IGTFP, factor structure $F S$ and labor structure $L S$ have significant positive effects on the IGTFP, and urban-rural structure URS is also positively related to IGTFP but not significantly. This indicates that the smaller the indicators of industrial structure and energy structure, and the larger the indicators of factor structure and labor structure, the faster the growth of the IGTFP. Put differently, structural optimization in the supply-side structural reform will improve the IGTFP. This result is basically consistent with the estimation results of the benchmark regression model, which indicates that the estimation results of this paper are relatively stable.

Table 6. Estimation results of the robustness tests.

\begin{tabular}{|c|c|c|c|}
\hline Variables & Meanings of Variables & (1) Adjusting Sample Period & (2) Removing Specific Samples \\
\hline IS & Industrial structure & $\begin{array}{c}-1.894^{* * *} \\
(0.347)\end{array}$ & $\begin{array}{c}-1.089 * * * \\
(0.274)\end{array}$ \\
\hline FS & Factor structure & $\begin{array}{c}0.046^{* * *} \\
(0.011)\end{array}$ & $\begin{array}{c}0.043^{* * *} \\
(0.009)\end{array}$ \\
\hline LS & Labor structure & $\begin{array}{c}0.028^{* * *} \\
(0.006)\end{array}$ & $\begin{array}{c}0.017^{* * *} \\
(0.006)\end{array}$ \\
\hline ES & Energy structure & $\begin{array}{c}-0.439 * * * \\
(0.116)\end{array}$ & $\begin{array}{c}-0.040 * * * \\
(0.012)\end{array}$ \\
\hline URS & Urban-rural structure & $\begin{array}{c}0.001 \\
(0.002)\end{array}$ & $\begin{array}{l}0.003 \text { * } \\
(0.002)\end{array}$ \\
\hline PGDP & GDP per capita & $\begin{array}{l}1.114^{* * *} \\
(0.159)\end{array}$ & $\begin{array}{c}0.396^{* * *} \\
(0.147)\end{array}$ \\
\hline OPEN & Opening-up degree & $\begin{array}{c}-0.567^{* * *} \\
(0.106)\end{array}$ & $\begin{array}{c}0.369^{* * *} \\
(0.127)\end{array}$ \\
\hline $\mathrm{RD}$ & Proportion of R\&D input & $\begin{array}{c}0.361^{* * *} \\
(0.044)\end{array}$ & $\begin{array}{c}0.067 \\
(0.049)\end{array}$ \\
\hline PATENT & $\begin{array}{c}\text { Number of patent } \\
\text { applications granted }\end{array}$ & $0.022^{* * *}$ & $0.053^{* * *}$ \\
\hline _cons & & $\begin{array}{c}(0.006) \\
-6.054^{* * *} \\
(1.070)\end{array}$ & $\begin{array}{r}(0.005) \\
-1.537 \\
(0.982)\end{array}$ \\
\hline Obs. & & 609 & 575 \\
\hline R-squared & & 0.564 & 0.600 \\
\hline
\end{tabular}

Note: The robustness tests are based on the following ways: (1) adjusting sample period (2) removing specific samples. Standard errors are in parenthesis. ${ }^{* * *} p<0.01,{ }^{* *} p<0.05,{ }^{*} p<0.1$. 


\subsubsection{Robustness Test by Removing Specific Samples}

According to the results of the analysis in Section 4.2.2, Beijing, Tianjin, Shanghai and other municipalities have the fastest growth in IGTFP. This may be prone to reverse causality problems and reduce the accuracy of the estimation results. Therefore, referring to Luo et al. and Song et al. [49,50], this paper further excludes the sample of municipalities and re-estimates it using the two-way fixed effects model, and the results are shown in column (2) in Table 6. The estimation results show that, among the core explanatory variables, the coefficients of industrial structure IS and energy structure $E S$ are negative and statistically significant, those of factor structure $F S$ and labor structure $L S$ are positive and statistically significant, and that of urban-rural structure URS is positive but not statistically significant. That is, the decreasing of industrial and energy structures and the increasing of factor and labor structures have significant positive effects on the growth of IGTFP. This result is consistent with the estimation results of the baseline regression model in Section 5.2. This indicates that structural optimization in supply-side structural reforms does have a significant positive effect on IGTFP, and further proves the robustness of the benchmark results in this paper.

\section{Conclusions and Policy Implications}

As the economy enters a new normal, China's economic and social development is facing a series of problems such as an imbalance in economic structure, environmental deterioration and widening income gap. At present, taking the supply-side structural reform as the mainline, promoting changes in economic development pattern and improving TFP are the keys to achieving high-quality development of the economy. In this context, this paper measures and analyzes the IGTFP in China's provinces from 1995 to 2017, and examines, for the first time, the contribution of structural optimization in supply-side structural reform to enhance IGTFP. The main findings obtained from this paper are as follows.

First, from 1995-2017, the average annual growth rate of IGTFP in China is $1.84 \%$, which is significantly smaller than that of traditional TFP without including environmental pollution and income disparity constraints $(2.5 \%)$. This suggests that China's real productivity may be overestimated. Although China's economy is growing, the quality of economic growth is low, and problems such as ecological degradation and income inequity are still relatively prominent. This has kept the growth rate of IGTFP at a low level. Therefore, China still faces greater pressure to achieve inclusive green economic growth.

Second, from a regional perspective, the average annual growth rate of China's IGTFP shows a stepped downward trend from east to west, with the average annual growth rates of IGTFP in the eastern, central and western regions being $3.64 \%, 1.27 \%$ and $0.61 \%$, respectively. This indicates that the environmental efficiency of economic growth in the eastern coastal region is higher and more inclusive, followed by the central region, while that in the western region is less efficient and less inclusive. Regional differences in the growth rates of IGTFP will further exacerbate the regional imbalance in China's economic development.

Third, the estimation results show that both industrial structure and energy structure have negative impacts on IGTFP in China, while factor structure, labor structure and urban-rural structure have positive effects on IGTFP. In other words, the smaller the indicators of industrial structure and energy structure, and the larger the indicators of factor structure, labor structure and urban-rural structure, the faster the growth of the IGTFP. Combined with the definition of each structural optimization indicator, these results imply that structural optimization in the supply-side structural reform will improve China's IGTFP.

Fourth, in the robustness tests, this paper re-estimates the model by both adjusting the sample period and excluding specific samples. The estimation results still show that structural optimization in the supply-side structural reform, represented by industrial structure, factor structure, labor structure, energy structure and urban-rural structure, will improve the IGTFP in China, indicating that our estimation results are relatively stable.

At present, China is in a critical period of economic transformation and should take the deepening of supply-side structural reform as the main line, comprehensively enhance 
IGTFP and promote high-quality economic development. Specifically, this paper puts forward the following policy implications.

First, China should actively promote the green and inclusive coordinated development of the regional economy. This paper finds that there are obvious regional differences in the IGTFP index in China's provinces. This may further aggravate the regional imbalance in China's economic development. Therefore, the government should attach great importance to the green and inclusive coordinated development of the regional economy. Firstly, according to our analysis results, the gap in technological progress may be the main reason for the faster growth of IGTFP in the eastern coastal region and the relatively slower growth in the northwest and northeast regions. Reducing the technological gap may be one of the key paths to narrowing the IGTFP gap across provinces. Therefore, it should make full use of the technological spillover effect of southeast coastal provinces and comprehensively improve the development level of high-tech and green technology in each province, thereby realizing the coordinated development of a green inclusive economy. Secondly, the government should guide and support the central and western regions to undertake industrial transfer and take the resource carrying capacity and ecological environmental capacity of these regions as an important basis for undertaking industrial transfer. This can prevent the problems of environmental pollution and ecological imbalance caused by industrial transfer, thus promoting the coordination of regional economic development with resources and the environment. Furthermore, in the context of supply-side reform, the government should improve the income distribution system, narrow the regional income gap and alleviate social inequality, so as to promote the coordinated development of various regions.

Second, China should further promote the optimization of the industrial structure. The estimation results show that industrial structure (characterized by the proportion of value added by secondary industry in GDP) has a significant negative impact on China's IGTFP. Therefore, China has great potential to improve the IGTFP by optimizing industrial structure. Firstly, the internal structure of the secondary industry should be improved. Some traditional manufacturing industries mainly rely on large amounts of resource inputs to achieve growth, resulting in great damage to resources and the environment. It should limit the rapid expansion of energy-intensive and high-emission industries by raising investment entry thresholds and establishing environmental regulatory mechanisms, encourage and support energy-intensive industries to achieve transformation and upgrading through technological innovation and technical innovation, and promote the development of manufacturing industries towards being technology intensive, high value added, low energy consuming and low carbon. Secondly, China should vigorously develop the service industry. Guide the traditional service industry to upgrade in the direction of modernization and high value added, strengthen the modern services, financial services, electronic information and other emerging services, so as to promote the sustainable development of the service industry. Thirdly, China should give priority to the development of industries that can provide broad employment opportunities, increase the income of the general public and improve people's living standards. This can further narrow the gap between the rich and the poor and promote inclusive economic growth.

Third, China should accelerate the optimization of energy structure. This paper finds that the estimated coefficient of energy structure, measured by the proportion of coal and crude oil consumption in total energy consumption, is significantly negative. This suggests that achieving cleaner substitution of high-pollution fossil energy and promoting energy structure transformation are conducive to the growth of China's IGTFP. At present, China is still in the process of industrialization and urbanization, its economy is developing faster and energy demand is expected to grow. Meanwhile, China's energy structure is still dominated by high-carbon fossil fuels, which will lead to environmental pollution and the increase in carbon emissions. Therefore, the adjustment and optimization of energy structure should be accelerated to promote inclusive green growth of China's economy. Firstly, it should promote the clean and efficient use of fossil energy. China's higher coal 
reserves dictate that the clean and efficient sustainable use of coal should be continuously promoted and carried out well. It is important to explore the potential of clean and efficient use of coal, achieve the low-carbon use of high-carbon energy and promote the high-quality development of the coal industry. Secondly, China should promote low-carbon energy to replace high-carbon energy and renewable energy to replace fossil energy, reduce the inefficient consumption of coal and increase significantly the proportion of non-fossil energy in the energy structure, especially wind, solar, water, biomass and other renewable energy, so as to move towards a stage of energy structure dominated by non-fossil energy.

Finally, improving scientific and technological innovation capacity and cultivating innovative talents helps to improve China's IGTFP. The estimation results show that increasing the proportion of highly educated workers and R\&D investment, and increasing the number of granted patent applications have significant positive effects on the growth of China's IGTFP. Therefore, China should continuously improve the capacity of scientific and technological innovation and cultivate high-level innovative talents to promote the inclusive green growth of China's economy. On the one hand, it should deepen the reform of the scientific and technological system, improve the national scientific and technological governance system, encourage enterprises and social capital to increase research investment and stimulate the innovation vitality of enterprises, universities and research institutes; it should guide the direction of green technology innovation, increase the support for green technology innovation, encourage and guide social capital to invest in green industries and build a green technology innovation system. On the other hand, it should deepen the reform of the research talent development system, improve the mechanism of discovering, cultivating and motivating innovative scientific and technological talents, enhance comprehensively the vitality of scientific and technological talents and build a high-level scientific and technological talent team; thus, further strengthening the cultivation of green technological innovation talents, solidifying the foundation of talents, enhance the technical level in the field of green technology and realize green sustainable development.

This study has the following limitations. Due to data limitations, this paper estimates and analyzes China's provincial IGTFP from 1995 to 2017 and examines the impact of economic structure optimization in China's supply-side structural reform on IGTFP at the provincial level. In fact, there are significant differences in the indicators in different cities within a province. If city-level data can be used, the evolution trend and distribution characteristics of China's IGTFP will be described in more detail. Meanwhile, using city-level data can also control the potential heterogeneity among cities and increase the sample size, thus revealing more accurately the impact of economic structure optimization on IGTFP. With the continuous improvement in data, city-level data should be considered for use in further studies.

Author Contributions: Conceptualization, F.W.; methodology, W.Z.; software, M.W.; data curation, J.W.; writing—original draft preparation, J.W., M.W., W.Z. and D.H.; writing—review and editing, F.W. and M.W.; visualization, M.W.; supervision, F.W.; project administration, F.W.; funding acquisition, F.W. All authors have read and agreed to the published version of the manuscript.

Funding: This research was funded by the National Natural Science Foundation of China [grant number 71673217] and the Research Project of Humanities and Social Sciences of the Ministry of Education of People's Republic of China in 2021 [grant number 21XJA790004].

Institutional Review Board Statement: Not applicable.

Informed Consent Statement: Not applicable.

Data Availability Statement: Not applicable.

Acknowledgments: The authors acknowledge financial support from the National Natural Science Foundation of China [grant number 71673217] and the Research Project of Humanities and Social Sciences of the Ministry of Education of People's Republic of China in 2021 [grant number 21XJA790004].

Conflicts of Interest: The authors declare no conflict of interest. 


\section{References}

1. Lu, Z.N.; Chen, H.; Hao, Y.; Wang, J.; Song, X.; Mok, T.M. The dynamic relationship between environmental pollution, economic development and public health: Evidence from China. J. Clean. Prod. 2017, 166, 134-147. [CrossRef]

2. Wei, S.J.; Wu, W.; Zhang, L. Portfolio choices, Asset returns and wealth inequality: Evidence from China. Emerg. Mark. Rev. 2019, 38, 423-437. [CrossRef]

3. Ge, T.; Qiu, W.; Li, J.; Hao, X. The impact of environmental regulation efficiency loss on inclusive growth: Evidence from China. J. Environ. Manag. 2020, 268, 110700. [CrossRef] [PubMed]

4. Khoday, K.; Perch, L. China and the World: South-South Cooperation for Inclusive Green Growth. 2020. Available online: https://ipcig.org/publication/26649?language_content_entity=en (accessed on 11 November 2021).

5. Li, G.; Feng, C. The effects of supply side structural reforms to the logistics industry. AIP Conf. Proc. 2017, 1834, 1-11.

6. Duran, H.E. Asymmetries in regional development: Does TFP or capital accumulation matter for spatial inequalities? J. Econ. Asymmetries 2019, 20, e00119. [CrossRef]

7. Chen, S.Y. Green industrial revolution in China: A perspective from the change of environmental total factor productivity. Econ. Res. J. 2010, 11, 21-34+58. (In Chinese)

8. Cao, X.; Deng, M.; Li, H. How does e-commerce city pilot improve green total factor productivity? Evidence from 230 cities in China. J. Environ. Manag. 2021, 289, 112520. [CrossRef]

9. Chen, S.; Golley, J. "Green” productivity growth in China's industrial economy. Energy Econ. 2014, 44, 89-98. [CrossRef]

10. Feng, Y.X.; Liang, Z.; Hu, S.; Xie, Y.; Wu, G. Effects of emission trading system on green total factor productivity in China: Empirical evidence from a quasi-natural experiment. J. Clean. Prod. 2021, 294, 126262. [CrossRef]

11. Jiang, Y.; Wang, H.; Liu, Z. The impact of the free trade zone on green total factor productivity-Evidence from the shanghai pilot free trade zone. Energy Policy 2021, 148, 112000. [CrossRef]

12. Li, B.; Wu, S. Effects of local and civil environmental regulation on green total factor productivity in China: A spatial Durbin econometric analysis. J. Clean. Prod. 2017, 153, 342-353. [CrossRef]

13. Shen, N.; Liao, H.; Deng, R.; Wang, Q. Different types of environmental regulations and the heterogeneous influence on the environmental total factor productivity: Empirical analysis of China's industry. J. Clean. Prod. 2019, 211, 171-184. [CrossRef]

14. Wu, H.; Li, Y.; Hao, Y.; Ren, S.; Zhang, P. Environmental decentralization, local government competition, and regional green development: Evidence from China. Sci. Total Environ. 2020, 708, 135085. [CrossRef]

15. Yu, D.; Li, X.; Yu, J.; Li, H. The impact of the spatial agglomeration of foreign direct investment on green total factor productivity of Chinese cities. J. Environ. Manag. 2021, 290, 112666. [CrossRef]

16. Yuan, B.; Xiang, Q. Environmental regulation, industrial innovation and green development of Chinese manufacturing: Based on an extended CDM model. J. Clean. Prod. 2018, 176, 895-908. [CrossRef]

17. Fan, J.S.; Yu, X.F.; Zhou, L. Urbanization, urban-rural gap and inclusive growth in China. J. Quant. Tech. Econ. 2018, 4, 41-60. (In Chinese)

18. Chen, H.L.; Qin, W.F. Inclusive growth in China: A perspective from the change of inclusive total factor productivity. China Ind. Econ. 2014, 1, 18-30. (In Chinese)

19. Aigner, D.; Lovell, C.A.K.; Schmidt, P. Formulation and estimation of stochastic frontier production function models. J. Econom. 1977, 6, 21-37. [CrossRef]

20. Arazmuradov, A.; Martini, G.; Scotti, D. Determinants of total factor productivity in former Soviet Union economies: A stochastic frontier approach. Econ. Syst. 2014, 38, 115-135. [CrossRef]

21. Odeck, J.; Schøyen, H. Productivity and convergence in Norwegian container seaports: An SFA-based Malmquist productivity index approach. Transp. Res. Part. A Policy Pract. 2020, 137, 222-239. [CrossRef]

22. Tu, Z.G.; Xiao, G. China's industrial productivity revolution-A stochastic frontier production function analysis of TFP growth in China's large and medium industrial enterprises. Econ. Res. J. 2005, 3, 4-15. (In Chinese)

23. Du, J.; Chen, Y.; Huang, Y. A modified Malmquist-Luenberger productivity index: Assessing environmental productivity performance in China. Eur. J. Oper. Res. 2018, 269, 171-187. [CrossRef]

24. Feng, C.; Huang, J.B.; Wang, M. The sustainability of China's metal industries: Features, challenges and future focuses. Resour. Policy 2019, 60, 215-224. [CrossRef]

25. Liu, D.; Zhu, X.; Wang, Y. China's agricultural green total factor productivity based on carbon emission: An analysis of evolution trend and influencing factors. J. Clean. Prod. 2021, 278, 123692. [CrossRef]

26. Lu, X.H.; Jiang, X.; Gong, M.Q. How land transfer marketization influence on green total factor productivity from the approach of industrial structure? Evidence from China. Land Use Policy 2020, 95, 104610. [CrossRef]

27. Qiu, S.; Wang, Z.; Geng, S. How do environmental regulation and foreign investment behavior affect green productivity growth in the industrial sector? An empirical test based on Chinese provincial panel data. J. Environ. Manag. 2021, 287, 112282. [CrossRef]

28. Wang, H.; Wang, M. Effects of technological innovation on energy efficiency in China: Evidence from dynamic panel of 284 cities. Sci. Total Environ. 2020, 709, 136172. [CrossRef]

29. Yan, P.F.; Wang, B. Technical efficiency, technical progress \& productivity growth: An empirical analysis based on DEA. Econ. Res. J. 2004, 12, 55-65. (In Chinese)

30. Li, S.; Fu, L.; Ma, Y. Higher education and productivity in China. Kuram ve Uygulamada Egit. Bilim. 2018, 18, 1863-1875. 
31. Sun, J.R.; Zhang, J.; Zhang, J.H.; Ma, J.H.; Zhang, Y.L. Total factor productivity assessment of Tourism industry: Evidence from China. Asia Pac. J. Tour. Res. 2015, 20, 280-294. [CrossRef]

32. Li, T.; Han, D.; Ding, Y.; Shi, Z. How Does the development of the internet affect green total factor productivity? Evidence from China. IEEE Access 2020, 8, 216477-216490. [CrossRef]

33. Liu, Z.; Xin, L. Has China's Belt and Road Initiative promoted its green total factor productivity?-Evidence from primary provinces along the route. Energy Policy 2019, 129, 360-369. [CrossRef]

34. Tao, F.; Li, L.; Xia, X.H. Industry efficiency and total factor productivity growth under resources and environmental constraint in China. Sci. World J. 2012, 2021, 1-10. [CrossRef]

35. Zhang, J.; Tan, W. Study on the green total factor productivity in main cities of China. Zb. Rad. Ekon. Fak. Rijeci 2016, 34, 215-234.

36. Xu, C.L.; Zhuang, G.Y. Dynamic structure and spatio-temporal effect of supply-side reform on industrial green development in China. Sci. Geogr. Sin. 2018, 38, 849-858.

37. Wang, S.H.; Yang, Z.W.; Liu, Y.; Zhang, W. The impact of R\&D Input, profitability and government regulation on Green Industrial Development in Beijing, Tianjin and Hebei-From the perspective of supply-side structural reform. Ind. Econ. 2021, 5, 33-38. (In Chinese)

38. Song, D.L.; Gao, X.Y.; Fan, X. Is Agricultural supply-side structural reform conducive to inclusive growth? J. East China Norm. Univ. Humanit. Soc. Sci. 2020, 1, 146-161. (In Chinese)

39. Zhang, C.; Zheng, C.J. The income distribution effect of industrial structure adjustment in the context of supply-side reform: An empirical analysis based on panel data of Zhejiang counties. Estate Obs. 2019, 3, 178-181. (In Chinese)

40. Färe, R.; Grosskopf, S.; Pasurka, C.A. Environmental production functions and environmental directional distance functions. Energy 2007, 32, 1055-1066. [CrossRef]

41. Chung, Y.H.; Färe, R.; Grosskopf, S. Productivity and undesirable outputs: A directional distance function approach. J. Environ. Manag. 1997, 51, 229-240. [CrossRef]

42. Färe, R.; Grosskopf, S. Measuring productivity: A comment. Int. J. Oper. Prod. Manag. 1994, 14, 83-88. [CrossRef]

43. Shan, H.J. Reestimating the capital stock of China:1952-2006. J. Quant. Tech. Econ. 2008, 10, 17-31. (In Chinese)

44. Chen, Y.; Zhang, J. Carbon emission, green total factor productivity and ecnomic growth. J. Quant. Tech. Econ. 2016, 8, 47-63. (In Chinese)

45. Zhang, H. Does the western development strategy reduce the rural-urban income disparity?-Evidence from regression discontinuity design. China J. Econ. 2020, 7, 162-193. (In Chinese)

46. Shao, C.L. An evaluation of the impact of western development strategy on urban-rural income gap: An empirical study based on difference in differences model. Mod. Financ. Econ. J. Tianjin Univ. Financ. Econ. 2014, 8, 26-33. (In Chinese)

47. Li, J.W.; Yang, Z.D. Impacts of technological innovation on the industrial structure, income distribution and possible solutions. Jilin Univ. J. Soc. Sci. Ed. 2013, 53, 5-11. (In Chinese)

48. Li, X.S.; Yu, Z.Y.; An, Q.X. Influencing analysis on Chinese provincial environmental total factor productivity. Chin. J. Manag. 2014, 11, 17-23. (In Chinese)

49. Luo, Y.; He, Q.; Xue, C. Impacts of law enforcement on financial development across Chinese regions. Econ. Res. J. 2016, 7, 118-131. (In Chinese)

50. Song, M.; Zhou, P.; Si, H.T. Financial technology and enterprise total factor productivity—Perspective of "Enabling" and Credit Rationing. China Ind. Econ. 2021, 4, 138-155. (In Chinese) 